Çukurova Üniversitesi Mühendislik Mimarlık Fakültesi Dergisi, 32(4), ss. 211-226, Aralık 2017

\title{
Mobilya Sektöründe Pnömatik Zımbalama ve Vidalama İşlerinin Ergonomik Risk Değerlendirmesi
}

\author{
Hale ALICI ${ }^{1}$, Hilal ATICI ULUSU ${ }^{2}$, Tülin GÜNDÜZ ${ }^{* 2}$ \\ ${ }^{1}$ Işı Üniversitesi, İs Sağll ̆̆g ve Güvenliği Yüksek Lisans Programı, İstanbul \\ ${ }^{2}$ Uludağ Üniversitesi, Mühendislik Fakültesi, Endüstri Mühendisliği Bölümü, Bursa
}

Öz

Geliş tarihi: 16.06.2017 Kabul tarihi: 19.12 .2017

Uygun olmayan çalışma duruşları kas iskelet sistemi rahatsızlıklarına neden olduğu gibi, üretimdeki verimin de düşmesine yol açmaktadır. Dolayısıyla ergonomi disiplininin öncelikli amacı, çalışma koşullarını iyileştirerek, iş görenin çalışma ve yaşam kalitesini yükseltmek ve verimliliği arttırmaktır. Kas iskelet sistemi rahatsızlıklarının önlenmesi amacıyla iş yerlerinde ergonomik risk değerlendirme yöntemleri uygulanmakta ve yapılan düzenlemelerle iş yükü azaltılmaktadır. Bu çalışmada, sıklıkla tekrarlanan statik ve dinamik duruşlara ve üst ekstremite pozisyonlarına göre seçilen REBA, OWAS, OCRA, QEC ve ManTRA yöntemleri mobilya imalatı yapılan bir atölyede uygulanmış, ergonomik açıdan risk oluşturabilecek pnömatik zımbalama ve pnömatik vidalama işlerinin risk değerlendirmesi yapılmıştır. Yapılan değerlendirmeler sonucunda, pnömatik zımbalama ve pnömatik vidalama işlerinde el, bilek, dirsek ve omuz gibi üst vücut bölgelerinin yoğun kullanıldığı ve teknik hareket sıklığının fazla olduğu durumlar için en uygun ergonomik risk değerlendirme yönteminin OCRA yöntemi olduğu sonucuna varılmıştır. OCRA yöntemi ile bir çevrim süresinin istasyonlara ayrılarak, her teknik hareketin tek tek analize dahil edilmesi detaylı bir değerlendirme yapılmasını sağlamıştır.

Anahtar Kelimeler: Ergonomik risk değerlendirme, Pnömatik zımbalama, Pnömatik vidalama, REBA, QEC, OCRA, OWAS, ManTRA

\section{Ergonomic Risk Assessment of Pneumatic Punching and Screwing Processes in the Furniture Industry}

\begin{abstract}
Unsuitable working postures cause musculoskeletal disorders, as well as a reduction in productivity. Therefore, the primary goal of the ergonomics is to improve working conditions and improve the working and living quality of the employee and increase productivity. In the workplaces, ergonomic risk assessment methods are implemented to prevent musculoskeletal disorders and so work load decreases.

In this study, REBA, OWAS, OCRA, QEC and ManTRA methods, which were selected according to frequently repeated static and dynamic postures and upper extremity positions, have been implemented in a factory manufacturing furniture and ergonomic risk assessment of pneumatic punching and pneumatic screw driving jobs which could create ergonomic risks were evaluated. As a result of the evaluation, for
\end{abstract}

"Sorumlu yazar (Corresponding author): Tülin GÜNDÜZ, tg@uludag.edu.tr 
those jobs like pneumatic punching and screw driving in which mostly hands, wrists, shoulders are used and in conditions which technical movements are mostly used, the most appropriate method for ergonomic risk assessment is OCRA. Using the OCRA method each cycle of work period is divided into stations and a detailed evaluation is made by involving of each technical movement.

Keywords: Ergonomic risk assessment, Pneumatic punching, Pneumatic screw driving, REBA, QEC, OCRA, OWAS, ManTRA

\section{GíRiș}

Teknolojik gelişmeler sonucu endüstride otomasyona geçişe rağmen, fiziksel insan gücüne duyulan ihtiyaç devam etmektedir. Yoğun insan gücü kullanımı gerektiren işlerde uygun olmayan çalışma duruşları, kas iskelet sistemi rahatsızlıklarına neden olduğu gibi üretim verimliliğini de olumsuz yönde etkilemektedir. Ergonominin temel amaçlarından biri; stres, zorlanma, yorgunluk ve iş kazalarını içeren maliyetlerin azaltılması ve böylece verimliliğin arttırılmasıdır. Ergonominin diğer bir amacı ise; çalışma duruşlarının iyileştirilmesi, çalışanın yetenekleri ve iş gerekleri arasındaki dengenin oluşturulması ile iş sağlığı ve güvenliğinin sağlanmasıdır [1]. Dolayısıyla hem işletme hem de çalışan açısından önemli bir konu olan çalışma duruşlarının incelenmesi ve değerlendirilmesi, ergonomi bilimi içerisinde önemli bir yer tutmaktadır.

İnsanın fiziksel ve zihinsel olarak belirli bir iş yapabilme gücü vardır. Kapasitesinin üzerinde çalıştırılan insanda solunum, dolaşım, kas iskelet sistemi ve merkezi sinir sisteminin zorlanması sonucu dinlenme ihtiyacı oluşur. Çalışanın yeteri kadar dinlenemediği durumlarda oluşacak fiziksel ve zihinsel yorgunluğa bağlı olarak iş kazaları ve meslek hastalıklarıyla karşılaşılma ihtimali artacak, iş verimi düşecektir [2].

Mesleki kas iskelet sistemi rahatsızlıkları, iş metotları ve çalışma ortamına bağlı olarak uygun olmayan ergonomik koşulların neden olduğu rahatsızlıklardır. Tekrarlı, yorucu ve ağır işlere uzun süreli maruziyet durumunda ortaya çıkan bu tip rahatsızlıklar; kas, sinir, tendon, bağ doku, eklem, kıkırdak ve spinal diskin yaralanması veya bozukluğu olarak tanımlanırlar [3]. Mesleki kas iskelet sistemi rahatsızlıkları, dünyadaki en yaygın sağlık sorunlarından biri olmasının yanı sıra; endüstride özellikle montaj hattı çalışanları arasında en sık görülen ve en fazla işgücü kaybına ve maliyete neden olan rahatsızlıklardır [4].

Çalışanda mesleki kas iskelet sistemi rahatsızlığına neden olan risk faktörlerine maruziyeti değerlendirebilmek için geliştirilen yöntemler; kişisel anket yöntemleri, sistematik gözlemlere dayalı yöntemler ve direkt ölçüm yöntemleri olmak üzere üç sınıfa ayrılmaktadır. Geçerlilik ve güvenilirlik açısından direkt ölçümler gözlemlerden, gözlemler ise kişisel anket yöntemlerinden daha iyidir. Direkt ölçüm yöntemleri, en doğru maruziyet seviyesini göstermektedir. Ancak diğer yöntemlerle kıyaslandığında maliyeti yüksektir. Kişisel anket yöntemleriyle, geniş bir popülasyona daha uygun bir maliyetle erişilebilmektedir, ancak anketler maruziyet seviyesi ve değişimi ile ilgili olarak düşük geçerliliğe sahiptir. Gözlem yöntemleri ise vücuda çeşitli cihazların takılmasını gerektiren direkt ölçüm yöntemlerinin aksine çalışanla teması gerektirmez ve vücut duruşlarının tanımlanmasında gözlemcinin yargılarına dayanır. Dolayısıyla gözleme dayalı yöntemler genellikle kişisel anket yöntemleriyle direkt ölçüm yöntemleri arasında dengeleyici olarak kullanılmaktadır [3].

Mevcut yöntemler ya iş istasyonundaki iş yükünü ya da çalışanın vücudunun iş yüküne tepkisini ölçmektedir. Yani bazı yöntemler dış yüklenmeyi (iş istasyonundaki iş yükü) değerlendirirken bazı yöntemler iç yüklenmeyi (çalışanın vücudunun iş yüküne tepkisi) değerlendirmektedir. İç yüklenmeyi değerlendiren yöntemler, direkt ölçüm yöntemleridir. Kalp hızı, kan basınc1, vücut 1sıs1, kas gerginliği gibi iç yüklenme göstergeleri, çalışanın kişisel özelliklerine ve kapasitesine göre 
farklılık göstermektedir. Diş yüklenmeyi değerlendiren yöntemlerden basit gözleme dayalı yöntemler; vücudun belli bir bölümünün duruşu, çalışanın uyguladığı kuvvet ve yüklenme zamanı parametrelerini kullanmaktadir. $\mathrm{Bu}$ yöntemlerin çoğu, iş sağlığ 1 ve güvenliği risk değerlendirmesi yöntemlerinden kullanım şekli ve amacı açısından farkl1l1k göstermektedir [6].

Bu çalışmada mobilya imalatı yapılan bir atölyede üretim aşamasında yapılan işler gözlemlenmiş, çalışanların kas iskelet sistemine zararlı etkileri olabileceği düşünülen pnömatik vidalama ve pnömatik zımbalama işlerinin ergonomik risk değerlendirmesinin yapılması amaçlanmıştır. $\mathrm{Bu}$ amaçla literatürdeki ergonomik risk değerlendirme yöntemleri araştırılarak, geçerliliği ispatlanmış yöntemler seçilmiş ve imalat atölyesinde uygulanarak, ergonomik açıdan risk oluşturabilecek işler analiz edilmiştir. Risk analizi için, çalışma sırasında sıklıkla tekrarlanan statik ve dinamik duruşlar ve özellikle üst ekstremite duruşları göz önüne alınarak REBA (Rapid Entire Body Assessment), OWAS (Ovako Working Posture Analysis System), OCRA (The Occupational Repetitive Action), QEC (Quick Exposure Check) ve ManTRA (Manual Tasks Risk Assessment Tool) yöntemleri uygulanmıştır.

$\mathrm{Bu}$ çalışmanın ergonomik risk değerlendirme yöntemlerini uygulayacak işletmelere kaynak oluşturması ve detaylı olarak incelenen yöntemlerle kullanıcılara kolaylık sağlaması amaçlanmıştır. Ayrıca çalışmada ele alınan işler veya benzer tipteki işlerin analizi için en uygun risk değerlendirme yönteminin belirlenmesi amaçlanmıştır.

\section{ERGONOMIK RISK DEĞERLENDİRME}

\subsection{REBA Yöntemi}

REBA veya Hızlı Tüm Vücut Değerlendirme, başta sağlık sektörü olmak üzere diğer hizmet sektörlerinde var olan öngörülemeyen çalışma duruşu türlerine duyarlı olacak şekilde 1999 yılında Hignett ve McAtamney tarafindan tasarlanmış ve geliştirilmiştir [7].

REBA yöntemi; işyerinde risk değerlendirmesi yapılırken duruş analizine ihtiyaç duyulduğunda,

1. Çalışma esnasında tüm vücudun kullanıldığı durumlarda,

2. Çalışma duruşunun statik, dinamik, tekrarlı veya değişken olduğu durumlarda,

3. Canlı ya da cansız yükler sıklıkla veya seyrek olarak elle taşındığında ve

4. İşyeri ve ekipman değişikliğinde, eğitimden önce ve sonra çalışanların risk alma algılarını gözlemlemek için kullanılabilmektedir [8].

\subsection{OWAS Yöntemi}

OWAS veya Ovako Çalışma Duruşları Analiz Sistemi, 1970'li yıllarda Finlandiya metal sektöründe geliştirilen ve çalışanın kas iskelet sistemindeki yüklenmeyi ve yapılan işin neden olduğu uygun olmayan duruşları değerlendiren gözleme dayalı bir analiz yöntemidir. OWAS yöntemi uygun olmayan duruşların ve görevlerin tespit edilmesi, çalışanın harcadığı kuvvete göre farklı çalışma sistemlerinin karşılaştırılması ve en uygun iş metotlarının geliştirilmesine imkân sağlamaktadır [1,9]. OWAS yönteminde gözlemci sırt, kollar, bacaklar ve yüklenme/kuvvet kullanımının kaydını 4 kod yardımıyla tutmaktadır. Her bir duruş için harcanan zaman ve o duruşun görülme sıklığı da değerlendirilmektedir.

OWAS eylem sınıfları, alınması gerekli düzeltici önlemlerin önceliğini ve aciliyetini göstermektedir. Eylem seviyesi, eylem ihtiyacının olmadığ 1 kodu ile acilen düzeltici önlemin alınmasını gerektiren 4 kodu aralığında değişmektedir. Belirli duruşların göreli oranı ve duruş birleşimleri, iyileştirme ihtiyacını belirlemek için dört eylem sınıfında verilmiştir ve bu eylem sınıfları risk seviyelerini göstermektedir [1,5].

\subsection{OCRA Yöntemi}

OCRA yönteminde üst vücut hareketlerinin ergonomik incelemesi yapılır. Özellikle el, bilek, 
dirsek ve omuz gibi temel üst vücut elemanlarının çalışma duruşları ve hareketleri OCRA indeksi ile yorumlanmaktadır. OCRA yönteminde bir istasyonda yapılan tüm işler için kümülatif bir analiz yapılır. OCRA indeksi hesaplanırken istasyonda birden fazla iş yapıllyorsa, bu işler için ayrı ayrı indeks hesaplanmaz, tüm istasyon için tek bir OCRA değeri hesaplanır. $\mathrm{Bu}$ sayede işlerin birbirleri üzerindeki kümülatif etkisi göz ardı edilmemiş olur $[10,11]$.

OCRA İndeksi, iş süresince gerçekleşen teknik hareket sıklığının, önerilen siklığa bölünmesi olarak ifade edilir (Eşitlik 1) [11].

$$
\text { OCRA İndeksi }=\frac{\text { Teknik Hareket Sıklığ } 1}{\text { Önerilen Sıklık }}
$$

OCRA'da tekrarlı iş olarak geçen işler, çevrim süresi boyunca tekrarlı olarak yapılan işlerdir. Teknik hareketler ise, bir işlemi gerçekleştirmek için yapılan hareket ettirme, uzanma, alma, kavrama, tutma, bırakma, yürüme, kontrol etme, döndürme, itme, çekme, kesme, başlatma, sonlandırma, boyama, zımparalama, çekiçle çakma gibi temel manuel hareketlerdir. Teknik hareket sıklığı Eşitlik 2 ile ve önerilen sıklık değeri Eşitlik 3 ile hesaplanabilir.

Teknik Hareket S1klığı=

$\underline{\text { Bir çevrimdeki teknik hareket sayısı*60 }}$ Çevrim Süresi

ÖNERILEN SIKLIK=SS*P*T*K*ERF*(DP*TIS)

Eşitlik 3'te yer alan yedi parametre sırasıyla sabit sıklık (SS), postur (P), tekrarlılık (T), kuvvet (K), ek risk faktörleri (ERF), yetersiz dinlenme periyodu (DP) ve tekrarlı işlerin bir vardiyadaki toplam süresidir (TİS). SS çarpanı sabit bir değerdir ve diğer tüm çarpanlar 0-1 arasında bir değer alır. İdeal koşullarda bu değerler 1 'dir ve ergonomik risk seviyesi arttıkça sıfıra yaklaşırlar. Elde edilen OCRA İndeks değeri risk değerlendirme tablosunda değerlendirilir. Buna göre işin risk seviyesine ve aksiyon alınıp alınmaması gerektiğine karar verilir [10].

\subsection{QEC Yöntemi}

QEC (Quick Exposure Check) veya Hizlı Maruziyet Değerlendirme yöntemi, 1998 yılında Li ve Buckle tarafından geliştirilen ve 2003 yılında David, Woods ve Buckle tarafından iyileştirilen bir ergonomik risk değerlendirme yöntemidir. QEC yüksek duyarlılığa ve kullanılabilirliğe sahiptir. Saha çalışmaları, geniş çeşitlilikte görevlere uygulanabileceğini göstermektedir [12,13].

QEC yönteminde her bir görev için maruziyet puanları, maruziyet puanları tablosu kullanılarak hesaplanmaktadır. Değerlendirme yapılırken öncelikle "Çalışan Değerlendirmesi Kontrol Listesi" ve "Gözlemci Değerlendirmesi Kontrol Listesi”nde tüm cevaplar daire içerisine alınır. Daha sonra daire içerisine alınan her harf çiftinin kesişme noktasındaki numara işaretlenir. Son olarak her bir vücut bölümü için toplam puan hesaplanır.

$E(\%)=\frac{x}{x_{\max }} * 100 \%$

QEC puanının hesaplandığı Eşitlik 4'te x, gerçek toplam maruziyet puanı ve $\mathrm{x}_{\max }$ mümkün en büyük toplam puanı ifade etmektedir.

\subsection{ManTRA Yöntemi}

ManTRA yöntemi Straker, Pollock, Egeskov ve Burgess-Limerick tarafından 2000 y1lında üst ekstremiteyi değerlendirmek üzere zorlanma indeksi (SI) yöntemine dayalı olarak geliştirilmiş ve 2004 yılında yayımlanmıştır [14]. Yöntemin geliştirilmesi aşamasında, araştırmanın bir parçası olan müfettişlerden ele alınan bir görevin toplam süresi ve görevin gerçekleştirildiği normal süre ile ilgili bilgileri toplamaları ve daha sonra farklı vücut bölümleri için beş görev özelliğinin (çevrim zamanı, kuvvet, hız, zorluk, titreşim) beş puanlı bir ölçek kullanarak yarı niceliksel olarak değerlendirmeleri istenmiştir. Süre ve çevrim zamanı puanları birleştirilerek "tekrarlama risk faktörü", aynı şekilde kuvvet ve hız puanları birleştirilerek "çaba risk faktörü" elde edilmiştir. Her bir risk faktörünün eşit ağırlık ve doğrusal bir ölçekte olduğu varsayılarak tekrarlama, çaba, 
zorluk, toplam zaman ve titreşim toplanmıştır. Yöntem, eylem gerektiren risk seviyelerini göstermektedir [15].

Sonuçta herhangi bir görev için;

- Çaba risk faktörü puan $1=5$

- Çaba risk faktörü puanı + Zorluk risk faktörü puan $1 \geq 8$

- $\quad$ Birikimli risk puan $1 \geq 15$ ise eylem önceliği mevcuttur [15].

\section{MATERYAL VE METOT}

Çalışmanın gerçekleştirildiği mobilya imalat atölyesi, 48 çalışanı bulunan ve baza üretimi yapan küçük ölçekli bir işletmedir. Atölyede çalışma saatleri 08.00 - 18.00 saatleri arasındadır, gün içinde 30 dakikalık bir yemek molası ve 15 dakikalık iki mola verilmektedir. Atölyede cumartesi günleri çalışılmamakta ve haftalık toplam çalışma süresi 45 saat olmaktadır. Bir günlük çalışma süresi boyunca 150 adet baza üretimi gerçekleştirilmekte ve her çalışanın tanımlı bir görevi bulunmaktadır.

Çalışmanın uygulama aşamasında, atölyede çalışanlar gün boyunca gözlemlenmiş ve risk değerlendirmesi yapılacak işlerin belirlenmesi için baza montajında ortaya çıkan çalışma duruşları incelenmiştir. Montaj sırasında sıklıkla tekrar eden vidalama ve zımbalama işleri için çevrim süreleri yaklaşık 1,5 dakika'dır ve günlük ortalama 150 adet baza bu şekilde montaj işlemlerinden geçmektedir. $\mathrm{Bu}$ işlemler esnasında çalışanlar eğilme, uzanma gibi hareketleri sıklıkla gerçekleştirmektedir. $\mathrm{Bu}$ şekilde bir çalışanın günde toplam yaklaşık 4 saat boyunca vidalama ve zımbalama işlemleri yaptığı ve riskli olabilecek duruşlarda çalışmak zorunda kaldığı görülmektedir. Dolayısıyla ergonomik risk değerlendirme yöntemleri ile analiz edilmek üzere pnömatik vidalama ve pnömatik zımbalama işleri ele alınmıştır.

Risk değerlendirmesi yapılmak üzere gözlemlenen işlerden ilki, Şekil 1'de görülen pnömatik vidalama işidir. Çevrim süresi boyunca bir bazanın pnömatik vidalama işi için, çalışanın harcadığı toplam süre 1 dakika 30 saniye'dir. Calıșan, montaj hattına gelen çelik profil karkası kaldırarak masanın üzerine koymakta, kumaş gergisi için mdf çıtaları profilin üst bölümüne, mdf plakaları ise profilin çevresine pnömatik vidalama aleti ile vidalamaktadır. Gözlemlenen ikinci iş, Şekil 2'de görülen pnömatik zımbalama işidir. Çevrim süresi boyunca bir bazanın pnömatik zımbalama işi için, çalışanın harcadığı toplam süre 1 dakika 36 saniye'dir. Çalışan, çıtalama işleminden gelen karkası dönme dolabın üzerine koymakta ve 50 $\mathrm{cm}$. genişliğindeki süngeri mdf plakalarının üzerine pnömatik zımbalama aleti ile zımbalamaktadır. Çalışanlar bu işlemleri her gün 150 adet baza için tekrarlamaktadır.

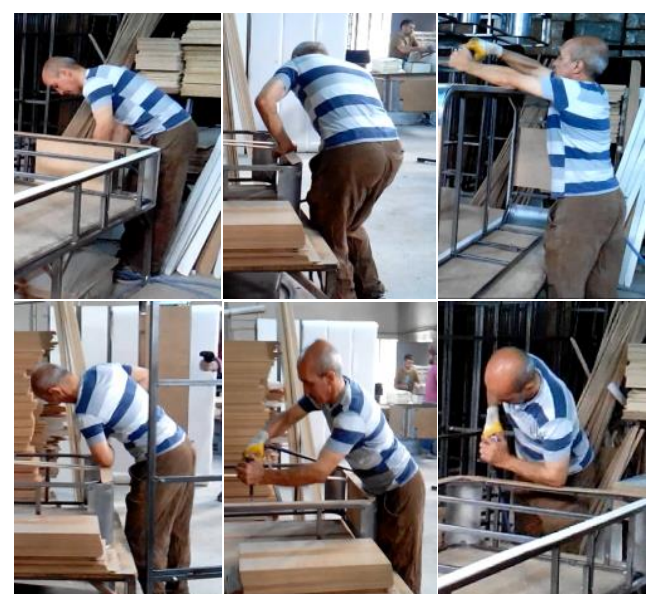

Şekil 1. Pnömatik vidalama işi

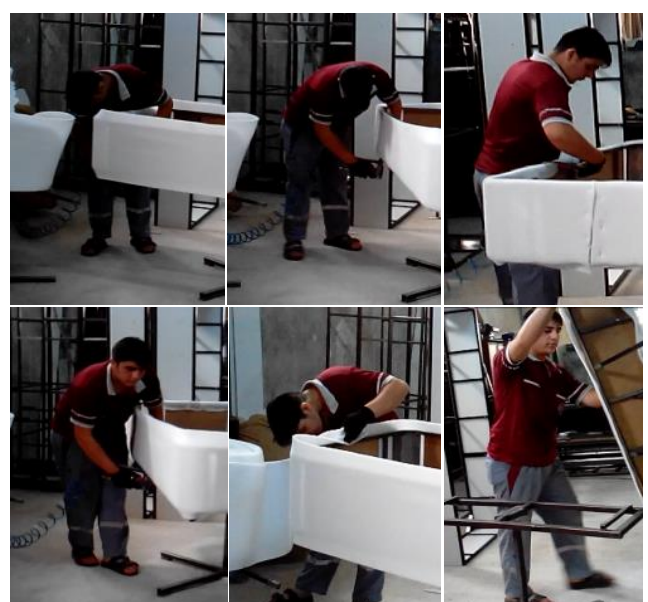

Şekil 2. Pnömatik zımbalama işi 


\section{BULGULAR}

Çalışmanın bu bölümünde, Materyal ve Metot bölümünde bahsedilen beş yöntemin pnömatik vidalama ve zımbalama işleri için uygulanmasıyla elde edilen bulgular açıklanmıştır.

\subsection{REBA Yönteminin Uygulama Sonuçları}

Şekil 1'de görülen vidalama işi için; detayları Çizelge 1'de verilen analiz sonucunda REBA skoru 12, REBA Eylem Seviyesi 4, risk seviyesi çok yüksek bulunmuş ve işi düzeltici önlemlerin acilen alınması gerektiği sonucu elde edilmiştir.

Şekil 2'de görülen zımbalama işi için de benzer şekilde detayları Çizelge 1'de verilen analiz sonucunda REBA skoru 11, REBA Eylem Seviyesi 4, risk seviyesi çok yüksek bulunmuş ve işi düzeltici önlemlerin acilen alınması gerektiği sonucu elde edilmiştir.

\subsection{OWAS Yönteminin Uygulama Sonuçları}

Vidalama işi için Şekil 1'de görüldüğü gibi çalışanın sırtı eğildiği ve eş zamanlı olarak döndüğü için kod 4; her iki kol da omuz seviyesinden yukarıda olduğu için kod 3; vidalama işi esnasında bacaktan kuvvet almak için, bir bacağın düz olduğu ve vücut ağırlığının tamamen bu bacakla desteklendiği durumu ifade ettiği için kod 3 seçilmiștir. Yüklenme/kuvvet duruşu için, kaldırılan ağırlık ya da ihtiyaç duyulan kuvvet 10 kg'dan az olduğu için kod 1 seçilmiştir (Çizelge 2). Eylem sinıfları tablosundan sirt, kol, bacak duruş kodları ve kuvvet kullanımı kodunun kombinasyonu yapıldığında eylem sinıfı 3 elde edilmektedir. OWAS Eylem Sinifi 3; yani kas iskelet sistemine zararlı etkilere sahip duruş olduğu için, mümkün olduğu kadar kısa zamanda işi düzeltici önlemlerin alınması gerektiği sonucu elde edilmiştir.

Zımbalama işinde Şekil 2'deki gibi çalışanın sırtı eğildiği ve eş zamanlı olarak döndüğü için kod 4; bir kol omuz seviyesinden yukarıda olduğu için kod 2; vücut ağırlığı iki düz bacak ile desteklendiği için kod 2 seçilmiştir. Yüklenme/kuvvet duruşu için, kaldırılan ağırlık ya da ihtiyaç duyulan kuvvet $10 \mathrm{~kg}$ 'dan az olduğu için kod 1 seçilmiştir (Çizelge 2). Bu kodlar ile eylem sinifları tablosundan eylem sinifi 2 elde edilmektedir. OWAS Eylem Sinıfi 2; yani kas iskelet sistemine bazı zararlı etkilere sahip duruş olduğu için, yakın bir zamanda işi düzeltici önlemlerin alınması gerektiği sonucu elde edilmiştir.

\subsection{OCRA Yönteminin Uygulama Sonuçları}

Vidalama işi için OCRA İndeksi hesaplanırken vücut hareketleri sağ ve sol için ayrı ayrı hesaplanmış ve daha kötü ergonomik durumu ifade eden sağ vücut hareketlerinin değerleri OCRA değeri olarak belirlenmiştir. 1 dakika 30 saniyelik bir çevrim süresi boyunca bir bazanın pnömatik vidalama işi için 4 istasyon belirlenmiştir. $\mathrm{Bu}$ istasyonlar;

1. Montaj bandına gelen çelik profil karkasın masanın üzerine konması,

2. Mdf çıtaların profilin üst bölümüne vidalanmas1,

3. Mdf plakaların profilin yanlarına vidalanması ve

4. Vidalama işlemi biten karkasın yerine konmasidır.

1. istasyonun 11 saniyelik istasyon süresinde 5 adet teknik hareket, 2. istasyonun 42 saniye'lik istasyon süresinde 17 adet teknik hareket, 3. istasyonun 27 saniye' lik istasyon süresinde 13 adet teknik hareket ve 4. istasyonun 10 saniye'lik istasyon süresinde 5 adet teknik hareket yapılmaktadır. Denklem 2 ile her istasyon için teknik hareket sıklığı hesaplanmıştır.

İstasyon 1 için teknik hareket sıklı̆ı̆ $=5 * 60 / 11=27,27$

İstasyon 2 için teknik hareket sıklığ $=17 * 60 / 42=24,29$

İstasyon 3 için teknik hareket sıklı̆̆ $=13 * 60 / 27=28,89$

İstasyon 4 için teknik hareket sıklığı $=5 * 60 / 10=30$ 
Çizelge 1. Pnömatik vidalama ve zımbalama işleri için REBA uygulaması

\begin{tabular}{|c|c|c|c|c|c|}
\hline \multicolumn{6}{|c|}{ Pnömatik Vidalama } \\
\hline \multicolumn{2}{|c|}{ A Grubu } & Tablo A & Tablo B & \multicolumn{2}{|r|}{ B Grubu } \\
\hline Gövde & $4+1$ & \multirow{3}{*}{9} & \multirow{3}{*}{8} & $4+1$ & Üst Kol \\
\hline Boyun & $2+1$ & & & 2 & Alt Kol \\
\hline Bacaklar & $2+2$ & & & $2+1$ & Bilek \\
\hline Yük/Kuvvet & & 0 & 0 & & Kavrama \\
\hline \multirow[t]{4}{*}{ A Skoru } & & 9 & 8 & & B Skoru \\
\hline & C Skoru & \multicolumn{2}{|c|}{11} & & \\
\hline & Aktivite Skoru & \multicolumn{2}{|c|}{1} & & \\
\hline & REBA Skoru & \multicolumn{2}{|c|}{12} & & \\
\hline \multicolumn{6}{|c|}{ Pnömatik Zımbalama } \\
\hline \multicolumn{2}{|c|}{ A Grubu } & Tablo A & Tablo B & & B Grubu \\
\hline Gövde & $4+1$ & \multirow{3}{*}{7} & \multirow{3}{*}{8} & $4+1$ & Üst Kol \\
\hline Boyun & $2+1$ & & & 2 & Alt Kol \\
\hline Bacaklar & 1 & & & $2+1$ & Bilek \\
\hline Yük/Kuvvet & & 0 & 0 & & Kavrama \\
\hline \multirow[t]{4}{*}{ A Skoru } & & 7 & 8 & & B Skoru \\
\hline & C Skoru & \multicolumn{2}{|c|}{10} & & \\
\hline & Aktivite Skoru & \multicolumn{2}{|c|}{1} & & \\
\hline & REBA Skoru & \multicolumn{2}{|c|}{11} & & \\
\hline
\end{tabular}
işleri için OWAS kodları

\begin{tabular}{|c|c|c|c|}
\hline \multicolumn{4}{|c|}{ Pnömatik Vidalama } \\
\hline $\begin{array}{l}\text { Sirt duruş } \\
\text { kodu } \\
\mathbf{4}\end{array}$ & $\begin{array}{c}\text { Kol duruş } \\
\text { kodu } \\
\mathbf{3}\end{array}$ & $\begin{array}{c}\text { Bacak } \\
\text { duruş kodu } \\
\mathbf{3}\end{array}$ & $\begin{array}{c}\text { Yüklenme/ } \\
\text { kuvvet } \\
\mathbf{1}\end{array}$ \\
\hline \multicolumn{4}{|c|}{ Pnömatik Zımbalama } \\
\hline $\begin{array}{l}\text { Sirt duruş } \\
\text { kodu } \\
\mathbf{4}\end{array}$ & $\begin{array}{c}\text { Kol duruş } \\
\text { kodu } \\
\mathbf{2}\end{array}$ & $\begin{array}{c}\text { Bacak } \\
\text { duruş kodu } \\
\mathbf{2}\end{array}$ & $\begin{array}{c}\text { Yüklenme/ } \\
\text { kuvvet } \\
\mathbf{1}\end{array}$ \\
\hline
\end{tabular}

Önerilen sıklı Denklem 3 kullanılarak hesaplanmıştır.

Önerilen sıklık=30x0,6x0,7x0,3x0,9x $(0,75 \times 1)=2,55$

Son olarak Denklem 1 kullanılarak her istasyon için OCRA İndeksleri hesaplanmıştır.

İstasyon 1 için OCRA İndeksi $=27,27 / 2,55=10,69$

İstasyon 2 için OCRA İndeksi $=24,29 / 2,55=9,53$

İstasyon 3 için OCRA İndeksi $=28,89 / 2,55=11,33$
İstasyon 4 için OCRA İndeksi $=30 / 2,55=11,76$

Tüm istasyonlardaki OCRA İndeks değeri 9,1 ve daha yüksek olduğu için risk seviyesi yüksek olarak belirlenmiş ve düzeltici eylemin acilen gerekli olduğu sonucuna varılmıştır.

Zımbalama işi için OCRA İndeksi hesaplanırken vücut hareketleri sağ ve sol için ayrı ayrı hesaplanmış ve daha kötü ergonomik durumu ifade eden sağ vücut hareketlerinin değerleri OCRA değeri olarak belirlenmiştir. 1 dakika 36 saniye'lik bir çevrim süresi boyunca bir bazanın pnömatik zımbalama işi için 4 istasyon belirlenmiştir. $\mathrm{Bu}$ istasyonlar;

1. Çitalama işleminden gelen karkasın dönme dolabın üzerine konması,

2. $50 \mathrm{~cm}$ genişliğindeki süngerin mdf plakaların üzerine çevrelenerek sarılması,

3. Süngerin mdf plakaların üzerine zimbalanması ve

4. Zımbalama işlemi biten karkasın yerine konmasıdır.

1. istasyonun 10 saniyelik istasyon süresinde 5 adet teknik hareket, 2. istasyonun 30 saniye'lik 
istasyon süresinde 9 adet teknik hareket, 3 . istasyonun 42 saniye'lik istasyon süresinde 13 adet teknik hareket ve 4 . istasyonun 14 saniye'lik istasyon süresinde 7 adet teknik hareket yapılmaktadır. Denklem 2 ile her istasyon için teknik hareket sıklığı hesaplanmıştır.

İstasyon 1 için teknik hareket sıklığı $=5 * 60 / 10=30$

İstasyon 2 için teknik hareket sıklığ $=9 * 60 / 30=18$

İstasyon 3 için teknik hareket sıklığ $1=$ $13 * 60 / 42=18,57$

İstasyon 4 için teknik hareket s1klığ $1=$ $7 * 60 / 14=30$

Önerilen sıklık Eşitlik 3 kullanılarak hesaplanmıştır.

Önerilen sıkl1k $=30 * 0,6 * 0,7 * 0,4 * 0,9 *(0,75 * 1)=3,40$

Denklem 1 kullanılarak her istasyon için OCRA İndeksleri hesaplanmıştır.

İstasyon 1 için OCRA İndeksi $=30 / 3,40=8,82$

İstasyon 2 için OCRA İndeksi $=18 / 3,40=5,29$

İstasyon 3 için OCRA İndeksi $=18,57 / 3,40=5,46$

İstasyon 4 için OCRA İndeksi $=30 / 3,40=8,82$

Tüm istasyonlardaki OCRA İndeks değeri 4,6-9,0 arasında olduğu için risk seviyesi orta olarak belirlenmiş ve düzeltici eylemin gerekli olduğu sonucuna varılmıştır.

El hareketlerinin tekrarlılığı ile ilgili yapılan bir çalışmaya göre; tekrarlılık veya OCRA yönteminde bahsedilen teknik hareket sıklığı, el hareketlerinin veya yüksek kuvvet uygulanan teknik hareketlerin frekansı ile tanımlanmaktadır. Ayrica kuvveti uygulama süresi, bir dakikada gerçekleştirilen hareket sayısı ve iş hızı belirleyici olmaktadır [16]. Bu çalıșmada incelenen pnömatik vidalama ve zımbalama ișlemlerinin her biri bir adet baza için yaklaşık 1,5 dakika'da tamamlanmaktadır. Dolayısıyla bu işlemlerde gerçekleştirilen üst vücut, kol ve el hareketlerinin frekans1 yüksek olduğundan OCRA uygun bir yöntem olmuştur.

\subsection{QEC Yönteminin Uygulama Sonuçları}

Pnömatik vidalama işi için QEC yöntemi uygulanırken çalışanın da katılımı sağlanmış ve Ek 1'de yer alan QEC yöntemi kullanıcı formu gözlemci ve çalışan tarafindan çift taraflı olarak değerlendirilmiştir. Ek 1'de verilen QEC Yöntemi Kullanıcı Formu değerlendirme sonucunda; çalışan değerlendirmesi Q'ya göre çalışan bu işi orta derecede stresli bulmuştur. Montaj bandına gelen çelik profil karkas seri bir şekilde vidalanıp, zımbalama işlemi için bandın diğer hattına yollanmakta ve zaman kaygısı çalışanda stres yaratmaktadır. Değerlendirme sonucunda toplam puan 131 olarak elde edilmiştir. Eşitlik 4 kullanılarak QEC puanı aşağıdaki gibi hesaplanmıştır.

QEC Puanı $=131 / 162 * 100=\% 80,86$

QEC puanı \% 70'in üzerinde olduğu için işin kas iskelet sistemi üzerinde etkileri araştırılmalı ve işi düzeltici önlemlerin acilen alınması gerekmektedir.

Pnömatik zımbalama işi için Ek 1'de yer alan QEC yöntemi kullanıcı formu gözlemci ve çalışan tarafından çift taraflı olarak değerlendirilmiştir. Ek 1'de verilen QEC Yöntemi Kullanıcı Formu değerlendirme sonucunda; toplam puan 122 olarak elde edilmiştir. Denklem 4 kullanılarak QEC puanı aşağıdaki gibi hesaplanmıştır.

QEC Puanı $=122 / 162 * 100=\% 75,31$

QEC puanı \% 70'in üzerinde olduğu için işin kas iskelet sistemi üzerinde etkileri araştırılmalı ve işi düzeltici önlemlerin acilen alınması gerekmektedir. 


\subsection{ManTRA Yönteminin Uygulama Sonuçları}

Çevrim süresi boyunca bir bazanın pnömatik vidalama işi için, çalışanın harcadığı toplam süre 1 dakika 30 saniye'dir. Çalışan bu görevi tüm gün yapmasına rağmen süreklilik faktörü dikkate alınmadığ için bu iş için harcanan toplam süre 225 dakika olmaktadır. Bir çevrim süresinde çalışanın sadece vidalama işi için harcadığı süre 75 saniye ve günlük 150 adet baza göz önüne alındığında toplamda harcanan süre 187,5 dakika olmaktadır. Çizelge 3'te ManTRA yöntemi kullanıcı formundan alınan değerler ile ManTRA puanlama matrisi doldurularak birikimli risk puanları elde edilmiştir. Yapılan değerlendirme sonucunda sırt, boyun/omuz, kol/bilek/el için birikimli risk puanı 15 'ten büyük olarak bulunmuştur dolayısıyla bu vücut bölgeleri için düzeltici eylem önceliği mevcuttur.

Bir bazanın zımbalama işi için çevrim süresi boyunca çalışanın harcadığı toplam süre ise 1 dakika 36 saniyedir. Süreklilik faktörü dikkate alınmadığı için bu iş için harcanan toplam süre 240 dakika olmaktadır. Bir çevrim süresinde çalışanın sadece vidalama işi için harcadığ 45 saniye ve günlük 150 adet baza göz önüne alındığında toplam harcanan süre 112,5 dakika olmaktadır. Çizelge 3'te ManTRA kullanıcı formundan alınan değerler ile ManTRA puanlama matrisi doldurularak birikimli risk puanları elde edilmiştir. Yapılan değerlendirme sonucunda sırt, boyun/omuz, kol/bilek/el için birikimli risk puanı
15 'ten büyük bulunmuştur dolayısıyla bu vücut bölgeleri için düzeltici eylem önceliği mevcuttur.

\section{DEĞERLENDİRME VE SONUÇ}

Uygun olmayan çalışma duruşları, önemsiz bel ağrılarından ağır engelliliğe kadar, mesleki kas iskelet sistemi rahatsızlıkları için öncelikli risk faktörlerinden birini oluşturmaktadır. Sorunun değerlendirilmesi ve azaltılması için proaktif adımların uygulanması önemlidir. $\mathrm{Bu}$ nedenle, mesleki kas iskelet sistemi rahatsızlıklarının ve bu rahatsızlıklara neden olan risk faktörlerinin erken belirlenmesi önemlidir. Daha uygun çalışma duruşları, kas iskelet sistemi üzerinde olumlu etkilere neden olmakta, çalışma performansının daha etkin kontrolüne izin vermekte ve iş kazalarını azaltabilmektedir [5].

$\mathrm{Bu}$ çalışmada ergonomik risk analizi yapmak üzere baza üretimi yapan bir mobilya imalat atölyesi seçilmiştir. Çalışmanın gerçekleştirildiği atölyede üretim bandı gözlemlenmiş ve iş yükünün fazla olduğu görülen pnömatik vidalama ve pnömatik zımbalama işleri ele alınmıştır. Sıklıkla tekrarlanan statik ve dinamik duruşlara ve üst ekstremite pozisyonlarına göre REBA, OWAS, OCRA, QEC, ManTRA yöntemlerinin uygulanmasına karar verilmiştir. $\mathrm{Bu}$ çalışma sonucunda elde edilen veriler işveren ve çalışanlarla paylaşılmış, düzeltici önlemler için çözüm önerileri geliştirilmesi planlanmıştır.

Çizelge 3. Vidalama ve zımbalama işleri için ManTRA puanlama matrisleri

\begin{tabular}{|c|c|c|c|c|c|c|c|c|c|c|}
\hline \multicolumn{11}{|c|}{ Pnömatik vidalama iși için ManTRA Puanlama Matrisi } \\
\hline & \multicolumn{9}{|c|}{ Görev Kodları } & \multirow[b]{2}{*}{$\begin{array}{l}\text { Birikimli } \\
\text { Risk }\end{array}$} \\
\hline $\begin{array}{l}\text { Vücut } \\
\text { Bölgesi }\end{array}$ & $\begin{array}{l}\text { Toplam } \\
\text { Zaman }\end{array}$ & Süre & $\begin{array}{l}\text { Çevrim } \\
\text { Zamanı }\end{array}$ & $\begin{array}{c}\text { Tekrarlama } \\
\text { Riski }\end{array}$ & Kuvvet & $\mathrm{H} 1 \mathrm{z}$ & $\begin{array}{l}\text { Çaba } \\
\text { Riski }\end{array}$ & Zorluk & Titreşim & \\
\hline Alt Ekstremite & 2 & 5 & 5 & 5 & 2 & 4 & 3 & 2 & 1 & 13 \\
\hline Sirt & 2 & 5 & 5 & 5 & 2 & 4 & 3 & 5 & 1 & 16 \\
\hline Boyun/Omuz & 2 & 5 & 5 & 5 & 4 & 4 & 5 & 5 & 1 & 18 \\
\hline Kol/Bilek/El & 2 & 5 & 5 & 5 & 5 & 4 & 5 & 5 & 1 & 18 \\
\hline \multicolumn{11}{|c|}{ Pnömatik zımbalama işi için ManTRA Puanlama Matrisi } \\
\hline & \multicolumn{9}{|c|}{ Görev Kodlar1 } & \multirow{2}{*}{$\begin{array}{c}\text { Birikimli } \\
\text { Risk }\end{array}$} \\
\hline $\begin{array}{l}\text { Vücut } \\
\text { Bölgesi }\end{array}$ & $\begin{array}{l}\text { Toplam } \\
\text { Zaman }\end{array}$ & Süre & $\begin{array}{l}\text { Çevrim } \\
\text { Zamanı }\end{array}$ & $\begin{array}{c}\text { Tekrarlama } \\
\text { Riski }\end{array}$ & Kuvvet & $\mathrm{Hiz}$ & $\begin{array}{l}\text { Çaba } \\
\text { Riski }\end{array}$ & Zorluk & Titreşim & \\
\hline Alt Ekstremite & 2 & 4 & 5 & 5 & 1 & 4 & 2 & 1 & 1 & 11 \\
\hline Sirt & 2 & 4 & 5 & 5 & 2 & 4 & 3 & 5 & 1 & 16 \\
\hline Boyun/Omuz & 2 & 4 & 5 & 5 & 2 & 4 & 3 & 5 & 1 & 16 \\
\hline Kol/Bilek/El & 2 & 4 & 5 & 5 & 4 & 4 & 5 & 5 & 1 & 18 \\
\hline
\end{tabular}


Risk faktörlerine dayalı olarak yapılan değerlendirme sonucunda, çalışanların yaptı̆̆ iş için de REBA ve QEC yöntemlerinde, eylem seviyesi açısından en yüksek puanlara ulaşılmıştır. OWAS yöntemi değerlendirme sonucunda risk değeri pnömatik vidalama işinde yüksek, pnömatik zımbalama işinde orta seviyede çıkmıştır. OWAS, tüm vücut duruşları ile taşınan yüke önem verdiği için daha çok güç ve vücudu kullanmayı gerektiren işlerde başarılıdır. Bu yönteme analiz esnasında baş da dahil edilebilmektedir ancak bilek ve dirseklerin değerlendirmeye katılmaması, el ve bilek hareketlerinin yoğun olduğu her iki iş için de uygun olmamaktadır. OWAS metoduna benzer olarak geliştirilen REBA yöntemi üst ekstremitenin daha detaylı incelenmesine olanak sağladığı için bu tip işler için OWAS metodu yerine REBA metodunu kullanmak daha doğru bir tercih olacaktır.

QEC yöntemi süreklilik faktörünü dikkate aldığ1 için OWAS ve REBA yöntemlerine göre daha tutarlı sonuçlar vermektedir. $\mathrm{Bu}$ çalışmada tüm vücut bölgeleri için toplam puan hesaplanmıştır ancak bel, boyun, omuz, bilek için ayrı olarak hesaplanan puanlar ile hangi vücut bölgesinin risk altında olduğu da hesaplanabilmektedir. Titreşim ve stres gibi faktörleri değerlendirmeye katması ve çalışanın katılımı sağlanarak değerlendirmenin çift taraflı yapılması yöntemin avantajıdır. Çalışanların katılımı ve iyileştirme önerileri değişimin uygulanmasına yardımcı olacaktır.

ManTRA yönteminde her iki iş için de sırt, boyun/omuz, kol/bilek/el bölgeleri için birikimli risk puanı yüksek çıkmıştır. Süreklilik faktörünü dikkate alması tutarlı sonuçlar vermekte, her bir vücut bölgesinin ayrı ayrı değerlendirilmesi, hangi vücut bölgesinin risk altında olduğunu göstermektedir. Ancak eylem seviyeleri hakkında bilgi vermemesi, eylemin aciliyeti hakkında değerlendirme yapılamamasına neden olmaktadır.

OCRA yöntemi ile risk değeri pnömatik vidalama işi için yüksek, pnömatik zımbalama işi için ise orta olarak bulunmuştur. Çalışmaya konu olan pnömatik vidalama ve pnömatik zımbalama işi gibi özellikle el, bilek, dirsek ve omuz gibi üst vücut bölgelerinin yoğun kullanıldığı durumlar için uygun bir ergonomik risk değerlendirme yöntemidir. OCRA yönteminde bir çevrim süresinin istasyonlara ayrılarak, her teknik hareketin tek tek analize dahil edilmesi detaylı bir değerlendirme yapılmasını sağlamaktadır. Bir istasyonda birden fazla iş yapıldığında tek bir indeks değerinin hesaplanması ile işlerin birbiri üzerindeki etkileri de dikkate alınmaktadır. Ayrıca vücudun sağ ve sol taraftan gözlemlenerek, ergonomik anlamda kötü durumda olan tarafın OCRA indeksi olarak alınması da önemli olmaktadır. Aydınlatma, koku, sıcaklık, psiko-sosyal faktörler gibi çalışma ortamından kaynaklanan ek risk faktörleri ile bir vardiya süresince mola vermeden çalışılan süreyi çarpan olarak dikkate alması bu yöntemle çok ayrıntılı ve tutarlı bir analize imkân vermektedir.

Yapılan değerlendirmeler sonucunda, çalışanların kas iskelet sistemine zararlı etkileri olabileceği düşünülen pnömatik zımbalama ve pnömatik vidalama işleri gibi üst vücut bölgelerinin yoğun kullanıldığı ve teknik hareket sıklığının fazla olduğu durumlar için en uygun risk değerlendirme yönteminin OCRA yöntemi olduğu sonucuna varılmıştır.

Bundan sonra yapılacak çalışmalarda, seçilen iş örneği için OCRA analizindeki risk skorunu en yüksek derecede etkileyen işlem noktalarına skoru düşürmeye yönelik metot değişikliği yapılması önerilmiştir. $\mathrm{Bu}$ çalışmada en tehlikeli ya da yüksek risk içeren iş bölümleri tespit edilip, kısa ve uzun vadede mesleki kas-iskelet sistemi rahatsızlıklarına maruz kalınmaması için hangi iş bölümlerinin üzerinde öncelikle çalışılması gerektiği belirlenmiştir.

\section{KAYNAKLAR}

1. Akay, D., Dağdeviren, M., Kurt, M., 2003. Çalışma Duruşlarının Ergonomik Analizi, Gazi Üniversitesi Mühendislik Mimarlık Fakültesi Dergisi, 18(3), 73-84.

2. Erkan, N., 1989. Çalışma Hayatında Fizyolojik Stresler ve Ergonomi. 2. Ulusal Ergonomi Kongresi (s. 31). Ankara: MPM Yayınları.

3. Özel, E., Çetik, O., 2010. Mesleki Görevlerin Ergonomik Analizinde Kullanılan Araçlar ve 
Bir Uygulama Örneği. Dumlupınar Üniversitesi Fen Bilimleri Enstitüsü Dergisi (22), 41-56.

4. Xu, Z., Ko, J., Cochran, D.J., Jung, M., 2012. Design of Assembly Lines with the Concurrent Consideration of Productivity and Upper Extremity Musculoskeletal Disorders using Linear Models, Computers and Industrial Engineering, 62, 431-441.

5. Karwowski, W., Marras, W.S., 1999. The Occupational Ergonomics Handbook. $1^{\text {st }}$ Edition, Florida: CRC Press.

6. Roman-Liu, D., 2013. Comparison of Concepts in Easy-to-use Methods for MSD Risk Assessment. Applied Ergonomics, 45(3), 420-427.

7. Hignett, S., McAtamney L., 2000. Rapid Entire Body Assessment (REBA). Applied Ergonomics, 31(2), 201-205.

8. Stanton, N., Hedge, A., Brookhuis, K., Salas E., Hendrick, H., 2005. Handbook of Human Factors and Ergonomics Methods, $1^{\text {st }}$ Edition, Florida: CRC Press.

9. Karhu, O., Kansi, P., Kuorinka, I., 1977. Correcting Working Postures in Industry: A Practical Method for Analysis, Applied Ergonomics, 8(4), 199-201.

10. Occhipinti, E., 1998. OCRA, A Concise Index for the Assessment of Exposure to Repetitive Movements of the Upper Limbs. Ergonomics, 41(9), 1290-1311.

11. Baykaşoğlu, A., Demirkol Akyol, Ş., 2014. Ergonomik Montaj Hattı Dengeleme, Gazi Üniversitesi Mühendislik Mimarlık Fakültesi Dergisi, 29(4), 785-792.

12. Li, G., Buckle, P., 1998. A Practical Method for the Assessment of Work-related Musculoskeletal Risks-Quick Exposure Check (QEC). Proceedings of the Human Factors and Ergonomics Society Annual Meeting, CA: SAGE Publications, 42(19), 1351-1355.

13. David, G., Woods, V., Li, G., Buckle, P., 2008. The Development of the Quick Exposure Check (QEC) for Assessing Exposure to Risk Factors for Work-related Musculoskeletal Disorders. Applied Ergonomics, 39(1), 57-69.

14. Straker, L., Burgess-Limerick, R., Pollock, C., Egeskov, R., 2004. A Randomized and Controlled Trial of a Participative Ergonomics
Intervention to Reduce Injuries Associated with Manual Tasks: Physical Risk and Legislative Compliance. Ergonomics, 47(2), 166-188.

15. Limerick, R.B., 2017. Further "Risk Assessment Methods" for Hazardous Manual Tasks, Cornell University Ergonomics, http://ergonomics.uq. edu.au/download/mantra2.pdf, 21 Mayıs 2017.

16. Bao, S., Howard, N., Spielholz, P., Silverstein, B., 2006. Quantifying Repetitive Hand Activity for Epidemiological Research on Musculoskeletal Disorders-Part II: Comparison of Different Methods of Measuring Force Level and Repetitiveness. Ergonomics, 49(4), 381-392. 
EK 1. QEC Yöntemi Uygulama

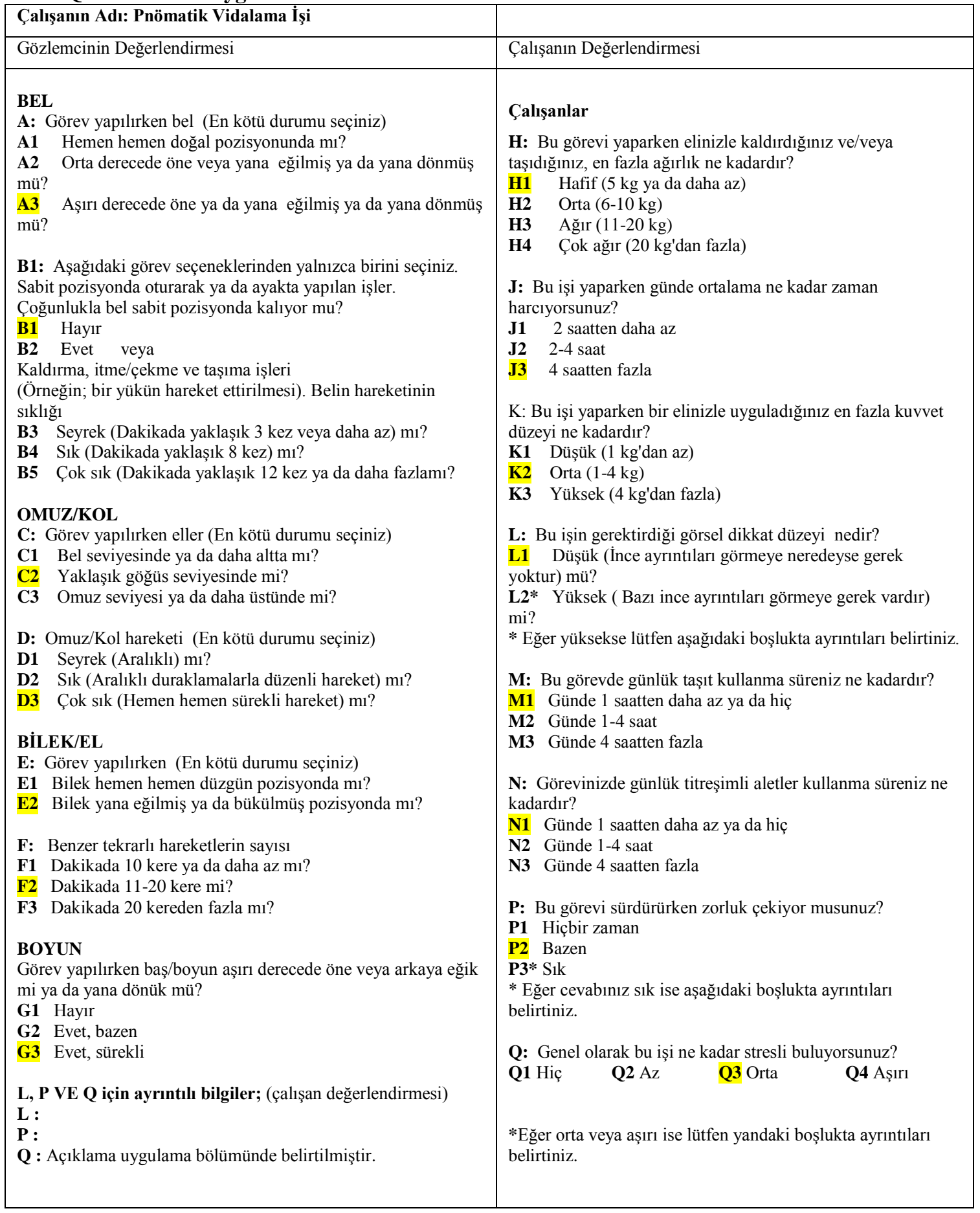




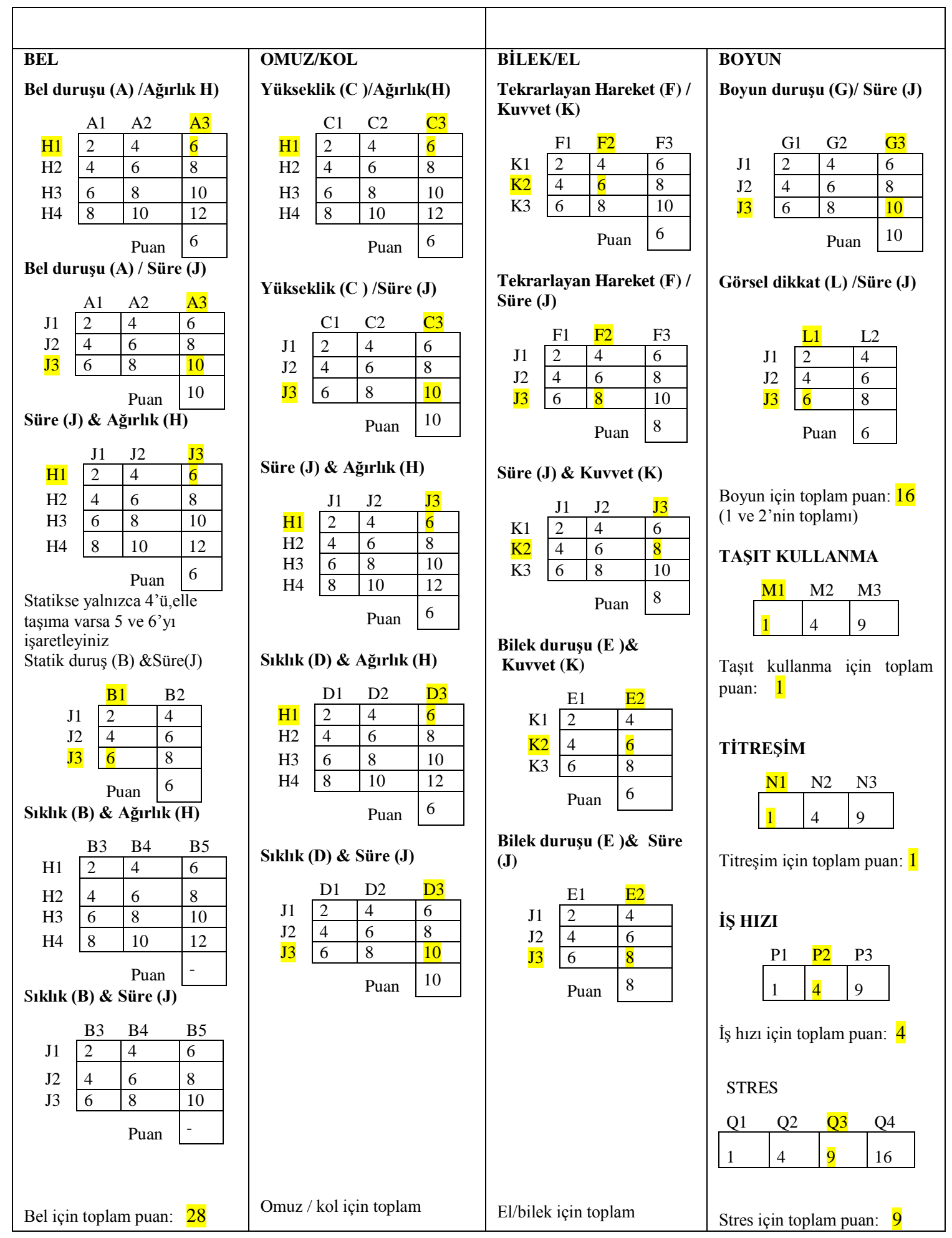




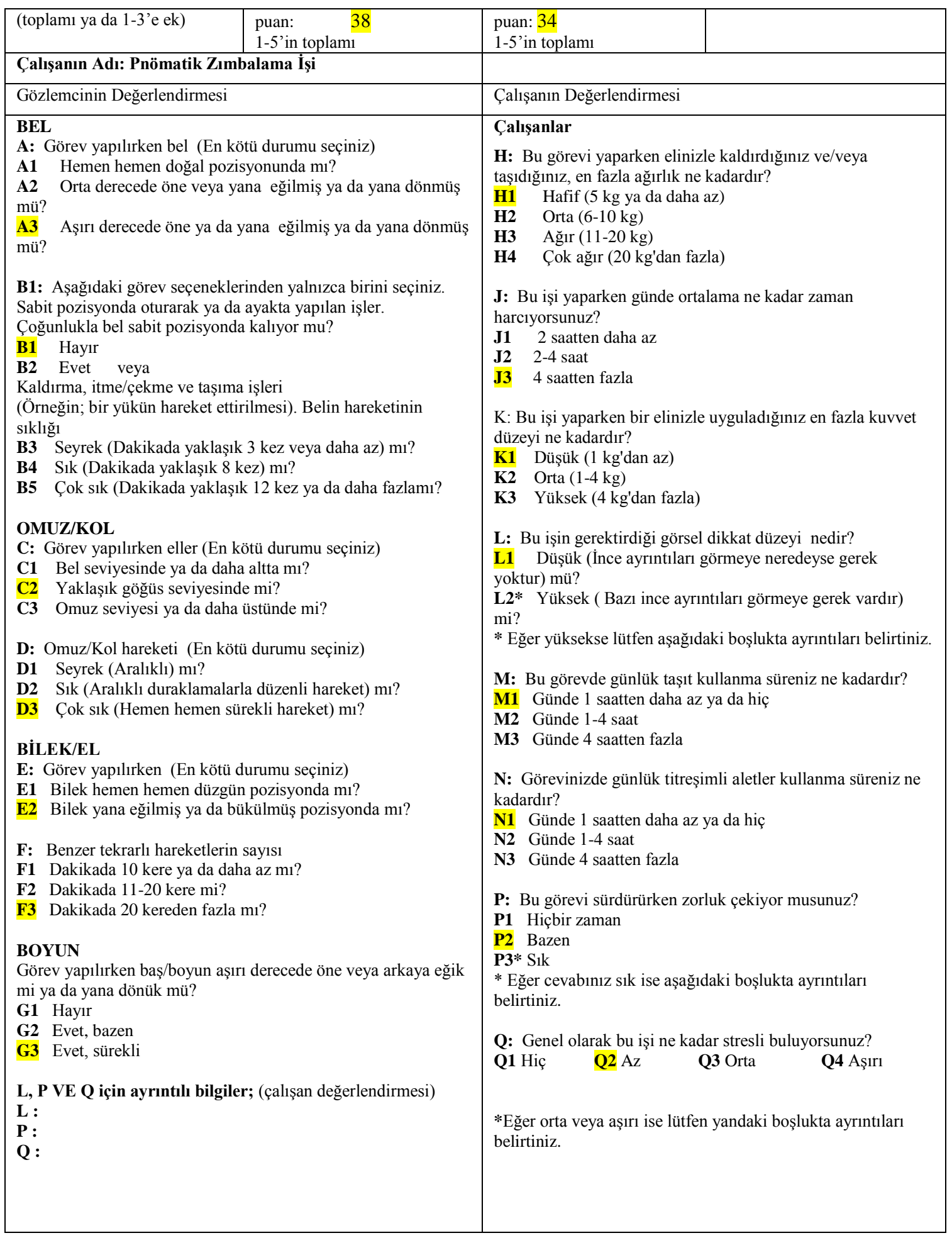




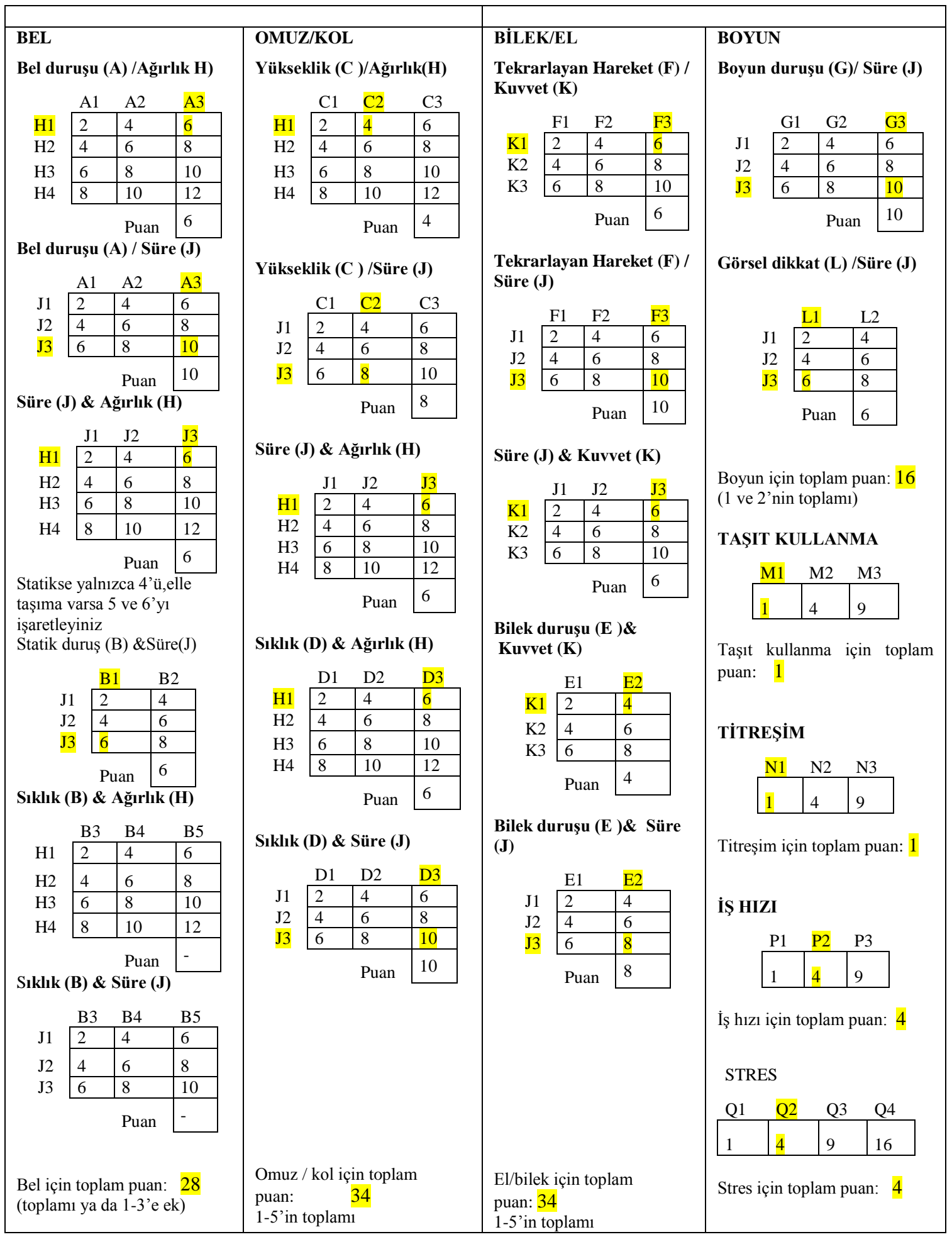


